Communications in Physics, Vol. 30, No. 2 (2020), pp. 161-170

DOI:10.15625/0868-3166/30/2/14801

\title{
FACILE SYNTHESIS OF CUO/ITO FILM VIA THE CHRONOAMPEROMETRIC ELECTRODEPOSITION FOR NONENZYMATIC GLUCOSE SENSING
}

\section{TRAN THI THUY DUONG ${ }^{1,2}$, NGUYEN QUOC DUNG ${ }^{3, \dagger}$, TRAN DAI LAM ${ }^{2,4}$ PHAM HONG CHUYEN ${ }^{3}$ AND NGUYEN TIEN DAI ${ }^{5}$}

${ }^{1}$ Faculty of Basic Science -Thai Nguyen University of Agriculture and Forestry, Vietnam

${ }^{2}$ Graduate University of Science and Technology, VAST, 18 Hoang Quoc Viet, Hanoi, Vietnam

${ }^{3}$ Department of Chemistry, Thai Nguyen University of Education

${ }^{4}$ Institute for Tropical Technology, Vietnam Academy of Science and Technology, Vietnam

${ }^{5}$ Institute of Theoretical and Applied Research, Duy Tan University, Hanoi, 100000, Vietnam

${ }^{\dagger} E$-mail: dungnq@tnue.edu.vn

Received 3 February 2020

Accepted for publication 21 April 2020

Published 14 May 2020

\begin{abstract}
We report on the synthesis of copper (II) oxide $(\mathrm{CuO})$ /indium tin oxide (ITO) electrode via the electrochemical deposition method using a $\mathrm{CuSO}_{4}$ solution and then thermal oxidation in air at temperature of $400^{\circ} \mathrm{C}$ for $2 \mathrm{~h}$. The crystalline structure and morphology of $\mathrm{CuO}$ were characterized by scanning electron microscope (SEM), energy-dispersive X-ray spectroscopy (EDS), and $X$-ray diffraction (XRD). The electrochemical properties of the CuO/ITO electrode to glucose in the alkaline medium of $0.1 \mathrm{M} \mathrm{NaOH}$ solution were investigated by cyclic voltammetry $(\mathrm{CV})$ and Chronnoamperometry. The CuO-N/ITO electrode showed the best electrochemical properties for glucose detection in comparison to the others. Chronnoamperometry of $\mathrm{CuO}-\mathrm{N} / \mathrm{ITO}$ electrode to the glucose response showed excellent stability, the linear range of $1 \mu \mathrm{M}$ to $3600 \mu \mathrm{M}$ with high sensitivity of $283.6 \mu \mathrm{Acm}^{-2} \mathrm{mM}^{-1}$ and $0.61 \mu \mathrm{M}$ of the detection limit $(S / N=3)$. A good response of the $\mathrm{CuO}$-N/ITO electrode, which was investigated for different human serum samples, indicates a high potential of its towards a glucose sensor for analysis in real examples.
\end{abstract}

Keywords: copper (II) oxide, glucose sensing, chronoamperometry, cyclic voltammetry, human serum.

Classification numbers: 73.50.Pz; 81.15.Pq; 82.45.Qr.

(C)2020 Vietnam Academy of Science and Technology 


\section{INTRODUCTION}

Glucose biosensors have been received much attention due to their importance in diabetes diagnosis, food industries, and environmental control [1-4]. The enzymatic glucose sensor, which was first demonstrated by Clark and Lyons [5] in 1962, has now developed to the third generation [6] with many advantages such as high sensitivity, good selectivity, and low detection limit. However, the enzyme is sensitive to temperature, $p H$, and toxic environment due to its intrinsic nature, resulting in the restriction of enzyme electrode applications [2-4]. For solving limitations, a fourth-generation biosensor with replacing enzyme electrodes by metallic electrodes as a glucose detector at low potential has been developed [7-9]. Noble metals (Pt, $\mathrm{Au}, \mathrm{Pd}$, etc.) have been investigated; however, these electrodes still have some drawbacks such as slow kinetics, poor selectivity, and effect by the poisoning of chloride ions [7,9]. Copper oxides with nano- and microstructures [7,9-14] or composites using either graphene or carbon nanotubes or gold with copper, etc. [15-21] as non enzymatic electrodes for glucose determination have been recently interested because of its good characters such as wide response range, low detection limits, stability, and immunity to the poisoning of chloride ions.

The fabrication of $\mathrm{CuO}$ electrodes includes two steps: (2) the high dispersion of the starting material in a solvent and then (2) the adhesion of the starting material onto the substrate by techniques of embedding, spin-coating, and drop-casting [22-24]. The disadvantage of embedding and drop-casting techniques are weak repeatability and the non-uniform surface of the electrode. The spin coating method requires the substrate is square or circle; thus, it is not suitable to fabricate the electrode [22]. Directly deposition of $\mathrm{Cu}$ onto the substrate by the physical vapor deposition (PVD) and chemical vapor deposition (CVD) methods require high temperature, complicated equipment, expensive, and toxic [25-27]. Even though the sputtering method is conducted at low temperatures, the crystal structure of production is hard to control. Nevertheless, it is still quite challenging to ensure a facile and reproducible fabrication of $\mathrm{CuO}$ electrodes.

Therefore, in this work, we investigated the fabrication of the $\mathrm{CuO} / \mathrm{ITO}$ electrode by a facile two-step process: (i) the $\mathrm{Cu}$ electrodeposition on the ITO substrate; (ii) the thermal oxidation to convert $\mathrm{Cu}$ to $\mathrm{CuO}$. The as-synthesized $\mathrm{CuO}$ layer showed excellent adhesion on the ITO substrate, and the crystal structure of the as-synthesized $\mathrm{CuO}$ could be controlled by changing the electrolyte. The cyclic voltammetry was used to investigate the electrochemical properties of the $\mathrm{CuO} / \mathrm{ITO}$ electrode to glucose in the alkaline medium of $0.1 \mathrm{M} \mathrm{NaOH}$ solution. Besides, for practical purposes, the $\mathrm{CuO} / \mathrm{ITO}$ electrode was also tested with human serum samples.

\section{EXPERIMENT}

\section{II.1. Reagents and Materials}

D-glucose, sodium hydroxide, copper sulfate hexahydrate, sulfuric acid, and human serum were purchased from Sigma-Aldrich. All solutions were made using double distilled water. Prior to use, the indium tin oxide (ITO) substrate with a resistance of $6.5 \Omega / \mathrm{m}^{2}$, and a size of $0.5 \mathrm{~cm} \times$ $2.0 \mathrm{~cm}$ (Samsung Corning Co. Ltd., Seoul Korea) was rinsed with methanol and acetone and then with double distilled water.

\section{II.2. Preparation of the $\mathrm{CuO}$ thin film onto ITO substrate}

Herein, the chronoamperometric deposition of $\mathrm{CuO}$ thin-film on ITO substrate was 
conducted in two steps as follows: (i) $\mathrm{Cu}$ thin-film was deposited on the ITO substrate by electrochemical method; (ii) the conversion of $\mathrm{Cu}$ to $\mathrm{CuO}$ by calcination at temperature of $400^{\circ} \mathrm{C}$ in air. Three starting solutions for the preparation of $\mathrm{Cu}$ film were used: (2) $0.1 \mathrm{M} \mathrm{CuSO}_{4}$ without supporting electrolyte; (2) $0.1 \mathrm{M} \mathrm{CuSO}_{4}$ with a supporting electrolyte of $0.1 \mathrm{M} \mathrm{H}_{2} \mathrm{SO}_{4}$; and (3) $0.1 \mathrm{M} \mathrm{CuSO}_{4}$ with a supporting electrolyte of $0.1 \mathrm{M} \mathrm{Na}_{2} \mathrm{SO}_{4}$. The applied potential was at -0.6 $V$ (vs. $\mathrm{Ag} / \mathrm{AgCl}$ reference electrode). The electrodes were fabricated using the starting solution № 1, 2, and 3 were denoted as $\mathrm{CuO}-\mathrm{C} / \mathrm{ITO}, \mathrm{CuO}-\mathrm{H} / \mathrm{ITO}$, and CuO-N/ITO electrodes, respectively. Nonconductive epoxy was used to fix the electrode area of $0.5 \mathrm{~cm} \times 0.5 \mathrm{~cm}$.

\section{II.3. Structural characterization and electrochemical measurements}

The structure, morphology, and elemental composition characterizations of the as-synthesized electrodes were investigated by X-ray diffraction (XRD, Brucker D8 Advance diffractometer) scanning electron microscope (SEM, Hitachi S-4800) equipped with energy-dispersive X-ray spectroscopy (EDS). The potentiostat \& Galvanostat instrument (Autolab $302 \mathrm{~N}$ ) controlled by the Nova 1.10 software was used for electrochemical measurement in the three-electrode system. A fabricated electrode served as the working electrode, while a $\mathrm{Ag} / \mathrm{AgCl} \mid \mathrm{Cl}$ (saturated $\mathrm{KCl}$ ) electrode and $\mathrm{Pt}$ sheet were used for the reference and the counter electrodes, respectively. The cyclic voltammetry (CV) was used to study the electrochemical properties of the fabricated electrode. The quantification of the glucose concentration in the solution was investigated by the chronoamperometric method. To test the applicability for practical purposes, human serum samples were also prepared to determine glucose using the CuO-N/ITO electrode.

\section{RESULTS AND DISCUSSION}

\section{III.1. Copper deposition}

Cyclic voltammograms (C.V.s) were employed to study the response of $0.1 \mathrm{M} \mathrm{CuSO}_{4}$ solution with a scan rate of $20 \mathrm{mV} / \mathrm{s}$ under different supporting electrolytes. The effect of electrolyte supports cyclic voltammetry (from $+0.6 \mathrm{~V}$ to $-0.9 \mathrm{~V}$, the scan rate of $20 \mathrm{mV} / \mathrm{s}$ ) of the ITO electrode in $0.1 \mathrm{M} \mathrm{CuSO}_{4}$, as shown in Fig. 1. There was no current, initially, the potential of -0.019; $-0.113 ;-0.022 \mathrm{~V}$ was reached in solution of $0.1 \mathrm{M} \mathrm{CuSO}_{4}$ (solution 1 ); $0.1 \mathrm{M} \mathrm{CuSO}_{4}+0.1 \mathrm{M}$ $\mathrm{H}_{2} \mathrm{SO}_{4}$ (solution 2) and $0.1 \mathrm{M} \mathrm{CuSO}_{4}+0.1 \mathrm{M} \mathrm{Na}_{2} \mathrm{SO}_{4}$ (solution 3), respectively. At this voltage, the cathodic current started to increase and form peak $\mathrm{I}_{c}$ (for solution 2 and 3 ) at a potential that depended on the electrolyte support as following reaction (1):

$$
\mathrm{Cu}^{2+}+2 e \rightarrow \mathrm{Cu}
$$

In the case of solution № 1, I.C. peak (cathodic current peak) presents that was not electrolyte support. For the solutions, №2 and 3, the decaying cathodic current past the peak $I_{\text {.C. }}$ with a potential of $-0.474 \mathrm{~V}$ and $-0.411 \mathrm{~V}$, respectively obeys diffusion-controlled regime [28]. In reverse scan, the anodic current appeared and had an $I_{\text {.A. }}$ peak (anodic current peak) with a potential of $0.362 \mathrm{~V}, 0.366 \mathrm{~V}$, and $0.440 \mathrm{~V}$ for solutions №1, 2, and 3, respectively, that was related to oxidation of $\mathrm{Cu}$ formation in a forward scan. All of $\mathrm{CuO} / \mathrm{ITO}$ electrodes were fabricated using electrodeposition by the chronoamperometry method in 120 seconds at an applied potential of -0.6 $V$ (the current value was steady, as seen in Fig. 1) followed by the oxidation of $\mathrm{Cu}$ at temperature of $400^{\circ} \mathrm{C}$ in air. 


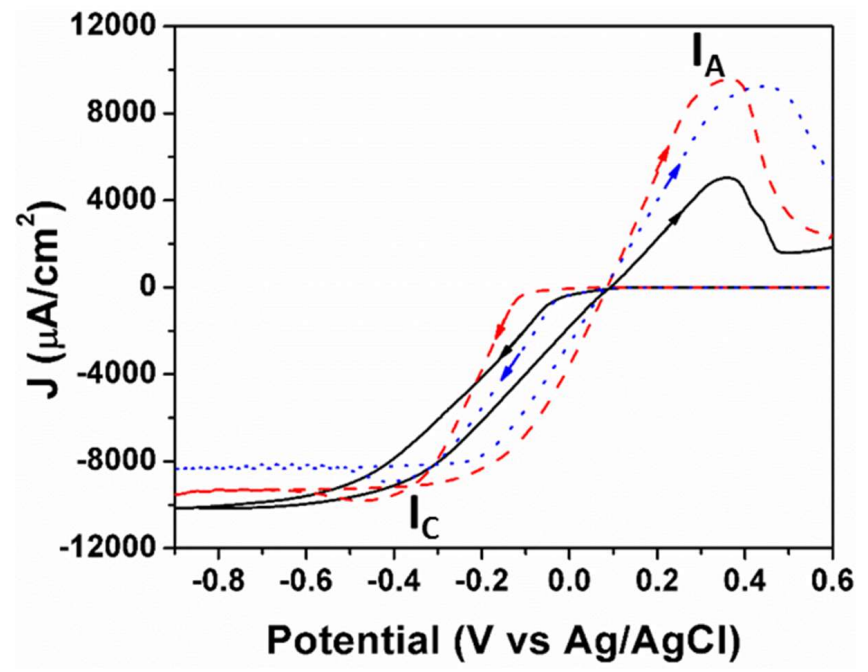

Fig. 1. Cyclic voltammograms (C.V.s) of $\mathrm{CuSO}_{4}$ under different electrolyte solutions. black curve: no supporting electrolyte, blue dot curve: supporting electrolyte of $0.1 \mathrm{M}$ $\mathrm{H}_{2} \mathrm{SO}_{4}$ and red dash curve: supporting electrolyte of $0.1 \mathrm{M} \mathrm{Na}_{2} \mathrm{SO}_{4}$.

\section{III.2. Structure and characterization}
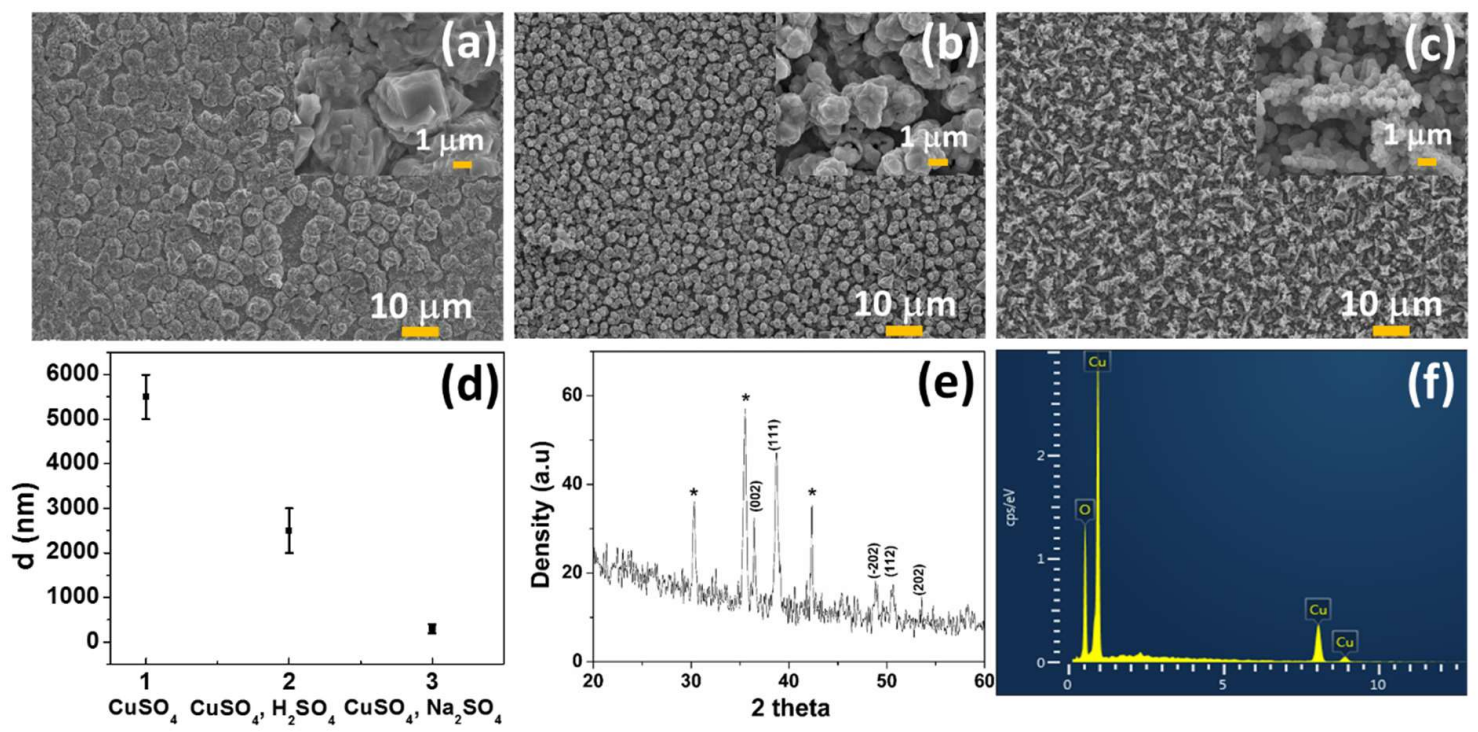

Fig. 2. SEM image of a) $\mathrm{CuO}-\mathrm{C}$, b) $\mathrm{CuO}-\mathrm{H}$, c) $\mathrm{CuO}-\mathrm{N}$, d), e) XRD pattern of $\mathrm{CuO}-\mathrm{N} / \mathrm{ITO}$ and (f) EDS analysis of CuO-N/ITO electrode.

Figure 2 presents SEM images of the $\mathrm{CuO}$ layer deposited on the ITO substrates. As a result, the starting solution considerably altered the morphology of $\mathrm{CuO}$. In Fig. 2(a), the as-prepared 
$\mathrm{Cu}$ morphology shows a sphere-like structure with particle size in a range of 5-6 $\mu \mathrm{m}$ while used only $0.1 \mathrm{M} \mathrm{CuSO}_{4}$ solution. Spherical $\mathrm{CuO}$ was also observed in CuO-H/ITO (Fig. 2(b)) and $\mathrm{CuO}-\mathrm{N} / \mathrm{ITO}$ (Fig. 2(c)) electrodes, but their particle size is smaller than that of $\mathrm{CuO}-\mathrm{C}$, implying that the supporting electrolyte could influence the formation of $\mathrm{CuO}$ crystalline particles. The particle size of $\mathrm{CuO}-\mathrm{H}$ and $\mathrm{CuO}-\mathrm{N}$ are in the range of 3-4 $\mu \mathrm{m}$ and $300-500 \mathrm{~nm}$, respectively. The smallest size of $\mathrm{CuO}-\mathrm{N}$ promised the best sensitivity of the $\mathrm{CuO}-\mathrm{N} / \mathrm{ITO}$ electrode in comparison with $\mathrm{CuO}-\mathrm{C} / \mathrm{ITO}$ and $\mathrm{CuO}-\mathrm{H} / \mathrm{ITO}$ electrodes. This excellent response is assigned to a higher electrochemical activity area when $\mathrm{CuO}$ particle size is smaller. Fig. 2(e) shows the XRD pattern of $\mathrm{CuO}-\mathrm{N}$ on the ITO substrate with $2 \theta$ diffraction peaks at $35.4^{\circ}, 38.5^{\circ}$, and $48.9^{\circ}$, indicating the monoclinic phase of $\mathrm{CuO}$ (JCPDS №045-0937). Fig. 2(f) shows EDS analysis of CuO-N sample, in which the atom ratio of $\mathrm{O}$ and $\mathrm{Cu}$ is roughly determined to be 55:45 in accordance with 1:1 ratio of $\mathrm{O}$ and $\mathrm{Cu}$ in $\mathrm{CuO}$. However, the atom ratio of $\mathrm{O}$ is higher than that of $\mathrm{Cu}$, which is attributed to the adsorption of oxygen on the $\mathrm{CuO}$ surface or the presence of $\mathrm{Cu}(\mathrm{OH})_{2}$, which is caused by the exposure of $\mathrm{CuO}$ surface to the environment moisture.

\section{III.3. Electrochemical properties}

\section{III.3.1. Selection of the supporting electrolyte in CuO/ITO electrode}

Figure 3 shows the cyclic voltammogram of $\mathrm{CuO}-\mathrm{C} / \mathrm{ITO}, \mathrm{CuO}-\mathrm{H} / \mathrm{ITO}$, and $\mathrm{CuO}-\mathrm{N} / \mathrm{ITO}$ electrodes measured in $0.1 \mathrm{M} \mathrm{NaOH}$ in the absence (black line curve) and presence (red dot curve) of $1 \mathrm{mM}$ glucose. Fig. 3(c) displays a glucose oxidation peak of $+0.52 \mathrm{~V}$ and one more small peak of $+0.60 \mathrm{~V}$ in the presence of $1 \mathrm{mM}$ glucose. In contrast, the unclear peak appeared for $\mathrm{CuO}-\mathrm{C} / \mathrm{ITO}$ and $\mathrm{CuO}-\mathrm{H} / \mathrm{ITO}$ electrodes that proved slow-kinetic of these electrodes in comparison with the $\mathrm{CuO}-\mathrm{N} / \mathrm{ITO}$ electrode. It is exciting after the background subtraction of cyclic voltammogram of electrodes by subtraction between $\mathrm{CV}$ signal of positive scan measured in $\mathrm{NaOH}$ solution with glucose and without glucose shows in Fig. 3(c). The faradaic current of glucose response was evident, with an oxidation peak at the potential of $0.52 \mathrm{~V}$. Thus, subtracted C.V.s current can be used to appraise the electrochemical properties of the electrodes. We can see the highest glucose response and the lowest glucose oxidation peak $(+0.52 \mathrm{~V})$ of the CuO-N/ITO electrode in comparison to the $\mathrm{CuO}-\mathrm{C} / \mathrm{ITO}$ electrode $(+0.63 \mathrm{~V})$ and the $\mathrm{CuO}-\mathrm{H} / \mathrm{ITO}$ electrode $(+0.61 \mathrm{~V})$. For further study, the CuO-N/ITO electrode was selected.

\section{III.3.2. Chronoamperometric detection to glucose of CuO-N/ITO electrode}

Based on the cyclic voltammogram of the CuO-N/ITO electrode, as shown in Fig. 3(c), even though the current peak of glucose oxidation was about $+0.52 \mathrm{~V}$ (vs. $\mathrm{Ag} / \mathrm{AgCl}$ ), for further studies, we selected a slightly lower potential, at $0.45 \mathrm{~V}$, for chronoamperometric measurement, to avoid the possible interference as in Ref. [2].

We utilized the chronoamperometric technique to quantify the glucose concentration in the solution in which a glucose oxidation potential was fixed, and the glucose oxidation current decayed versus time was recorded by Cottrel equation:

$$
i=\frac{n F A C^{0} \sqrt{D}}{\sqrt{\pi t}}
$$



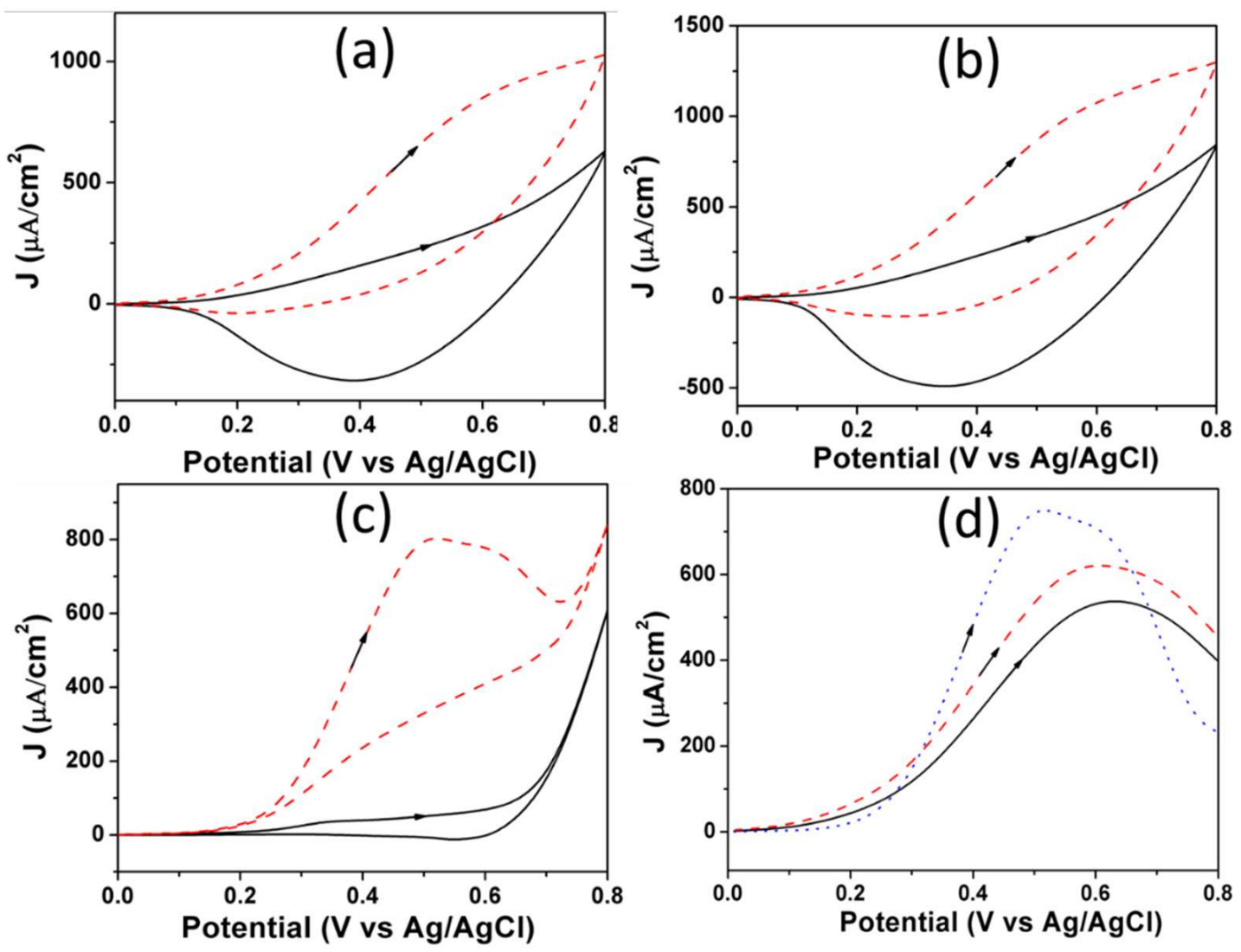

Fig. 3. Cyclic voltammograms of CuO-C/ITO (a), CuO-H/ITO (b), and CuO-N/ITO (c) electrodes in the absence (black line curve) and presence (red dot curve) of $1 \mathrm{mM}$ glucose; Background subtracted current of a positive scan of the electrodes for $1.0 \mathrm{mM}$ glucose response (d).

where $i$ is an electric current of the electrode with an area of $\mathrm{A}$ in the solution of analytical of $\mathrm{C}^{\circ}$ versus time $t$, diffusion coefficient $D$, and Faraday constant $F$.

$$
i=k \cdot t^{-1 / 2}
$$

where $k$ is the collection of constants for a given system $\left(n, F, A, \mathrm{C}^{\circ}, D\right)$.

Figures 4(a-c) shows the chronoamperometric measurement with $\mathrm{CuO}-\mathrm{N} / \mathrm{ITO}$ electrode in a $0.1 \mathrm{M} \mathrm{NaOH}$ solution at $0.45 \mathrm{~V}$ (vs. $\mathrm{Ag} / \mathrm{AgCl}$ ) with different glucose concentrations ranging from $0 \mu \mathrm{M}$ to $10 \mu \mathrm{M}$ in Fig. 4(a), from $0 \mu \mathrm{M}$ to $100 \mu \mathrm{M}$ in Fig. 4(b) and from $0 \mu \mathrm{M}$ to 600 $\mu \mathrm{M}$ in Fig. 4(c), more specific concentrations are not shown. The calibration curve of oxidation current density [(after 35 seconds of chronoamperometry curve, as shown in Figs. 4(a-c)] versus the glucose concentration in Fig. 4(d) exhibited linearity for glucose sensing in the range from 1 $\mu \mathrm{M}$ to $3600 \mu \mathrm{M}$ with a correlation coefficient $(R)$ of 0.9998 . According to the linear range, the 

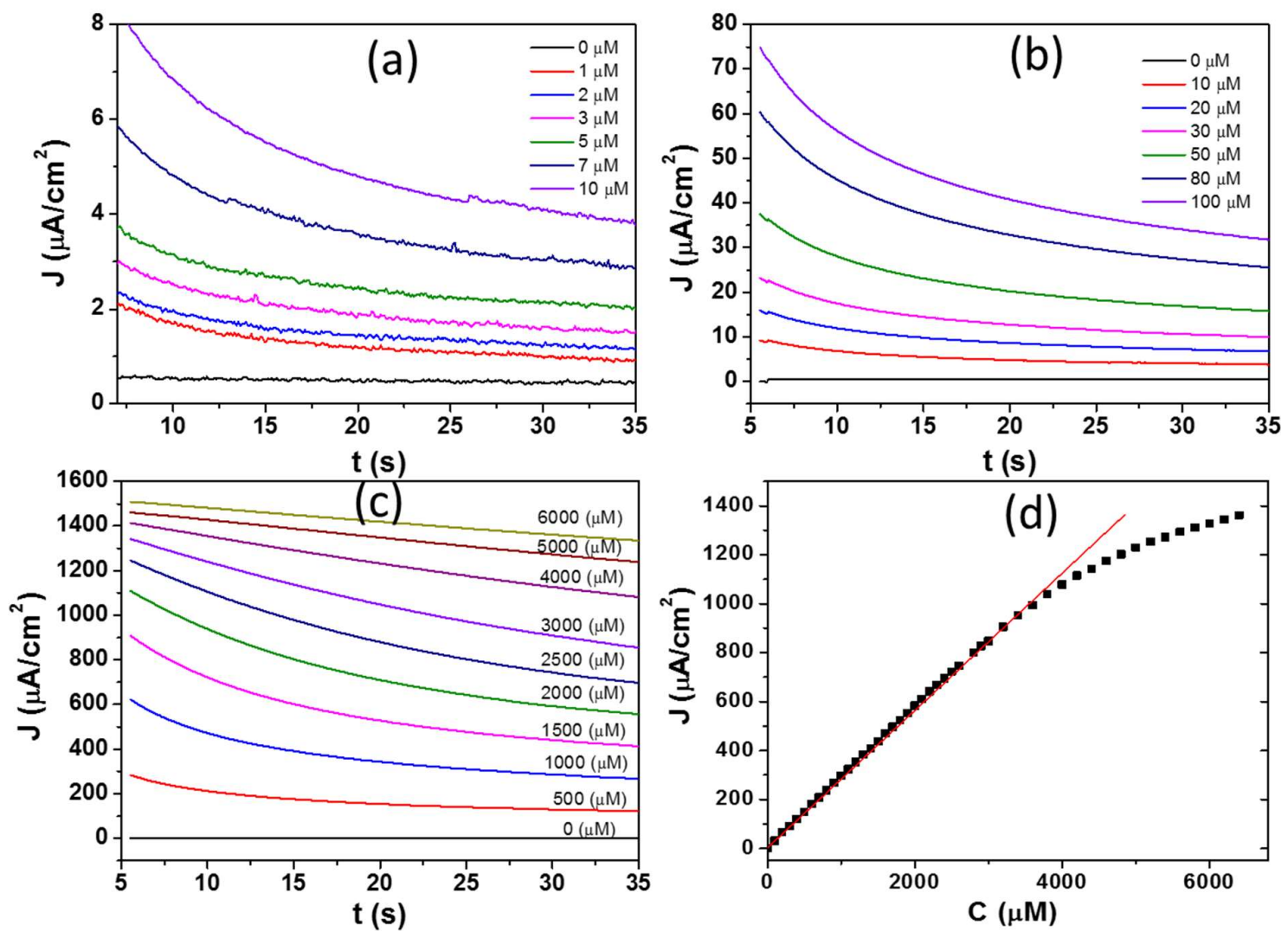

Fig. 4. The chronoamperometric response of $\mathrm{CuO}-\mathrm{N} / \mathrm{ITO}$ electrode at $0.45 \mathrm{~V}$ ( vs. $\mathrm{Ag} / \mathrm{AgCl}$ ) to different glucose concentration scale (a) $0 \mu \mathrm{M}$ to $10 \mu \mathrm{M}$; (b) $0 \mu \mathrm{M}$ to 100 $\mu \mathrm{M}$; (c) $0 \mu \mathrm{M}$ to $6000 \mu \mathrm{M}$ and (d) the calibration curve of dependence of the oxidation current density (after $35 \mathrm{~s}$ ) on glucose concentration.

slope of the calibration curve indicated the sensitivity $\left(283.6 \mu \mathrm{Acm}^{-2} \mathrm{mM}^{-1}\right)$ of the electrode and detection limit of $0.61 \mu \mathrm{M}$ (an estimate of signal to noise equals 3 ).

Additionally, the electrochemical response of the CuO-N/ITO electrode was investigated in solution containing of individual interfering species such sucrose, ascorbic acid (AA), and uric acid (UA) by applying of oxidation potential at $0.45 \mathrm{~V}$. Fig. 5 shows the specificity of the electrode by adding sucrose, UA, and AA of $50 \mu \mathrm{M}$ in $0.1 \mathrm{M} \mathrm{NaOH}$ solution containing $500 \mu \mathrm{M}$ glucose. The additional signals obtained as $0.75 \%, 6.63 \%$, and $3.86 \%$, for sucrose UA, and AA, respectively. Since the concentrations of the AA, and UA in the blood were 30 times less than glucose [2], the CuO-N/ITO electrode can be applied to determine glucose in human blood.

\section{III.3.3. Application of electrode in the human serum sample}

The CuO-N/ITO sensor electrode was investigated for human serum samples. The sample was prepared using water/or glucose mixing human serum samples to make different glucose concentrations. A human serum solution of $100 \mu \mathrm{L}$ was diluted in a $25 \mathrm{~mL} 0.1 \mathrm{M} \mathrm{NaOH}$ solution. 


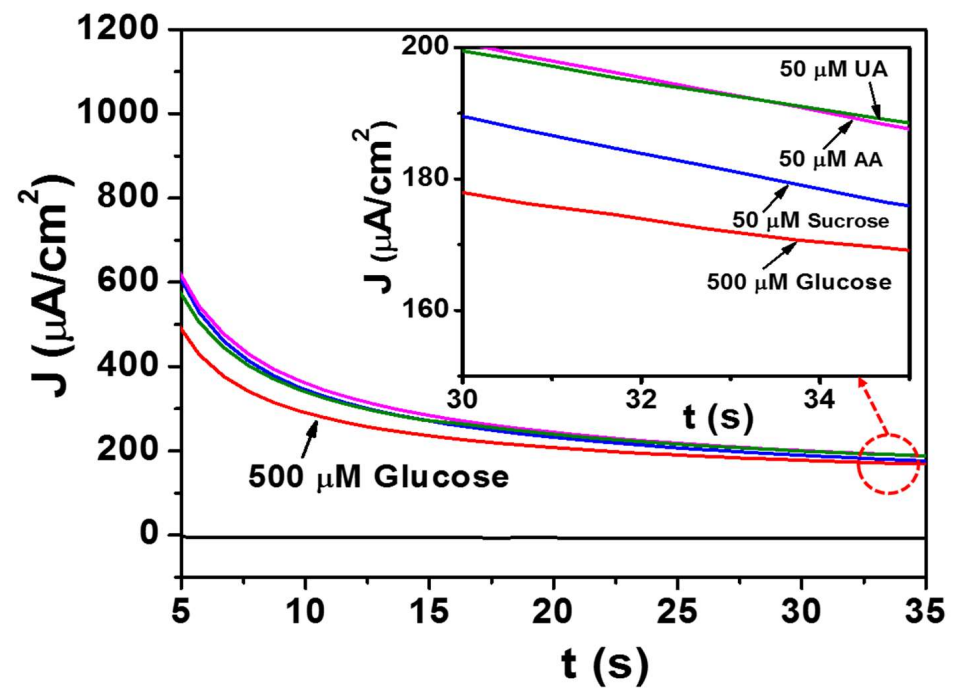

Fig. 5. The selectivity of CuO-N/ ITO electrode was examined by measuring responses to interfering species of sucrose, AA and UA at an applied potential of $0.45 \mathrm{~V}$ in $0.1 \mathrm{M}$ $\mathrm{NaOH}$.

The chronoamperometric response was recorded at a potential of $0.45 \mathrm{~V}$ that was shown in Fig. 6 . The solid black line and red dash line are corresponding to before and after adding the human serum sample, respectively. Based on the calibration curve (Fig. 4(d)), we calculated the glucose concentration and compared it with the prepared concentration listed in Table 1. The results indicate that the sensor is comparable with a commercial one (measured by RGII glucose meter), and the $\mathrm{CuO}-\mathrm{N} / \mathrm{ITO}$ electrode would be a useful approach for the development of non enzymatic glucose sensors for real samples.

Table 1. Comparison of CuO-N/ITO with RG II meter.

\begin{tabular}{cccc}
\hline Samples & $\begin{array}{l}\text { Glucose concentration by } \\
\text { RG II* meter }(\mathrm{mM})\end{array}$ & $\begin{array}{l}\text { Glucose conc. measured by } \\
\text { CuO-N/ITO (mM) }\end{array}$ & Deviation (\%) \\
\hline 1 & 4.91 & 5.41 & 10.2 \\
2 & 7.76 & 8.01 & 5.0 \\
3 & 9.73 & 9.84 & 1.2 \\
4 & 15.42 & 16.94 & 9.9 \\
\hline
\end{tabular}

* Glucose meter from Sejong Biotechnology (Korea)

Furthermore, the stable response of CuO-N/ITO electrodes for two months with $0.1 \mathrm{mM}$ glucose were investigated. The current density response of the electrodes showed a negligible change due to the high stability of the $\mathrm{CuO}$ phase in a glucose solution. This result suggests another approach for fabricating the stable, selective non enzymatic glucose sensor. 

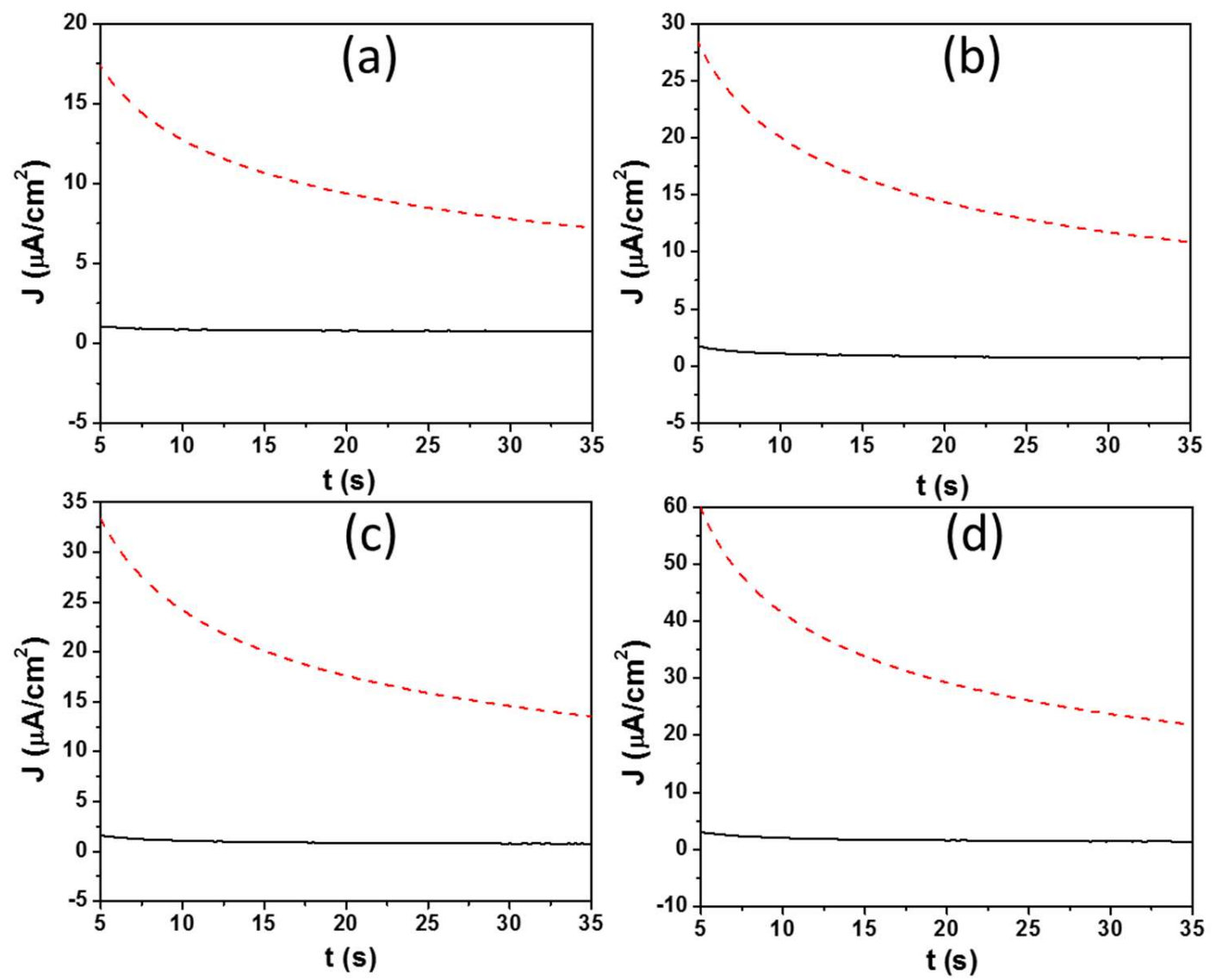

Fig. 6. The sensor was used for investigating human serum samples by the chronoamperometric method by adding $200 \mu \mathrm{L}$ human serum sample to $250 \mathrm{~mL} 0.1 \mathrm{M} \mathrm{NaOH}$ solution at $0.45 \mathrm{~V}$ (vs. $\mathrm{Ag} / \mathrm{AgCl}$ ) with different glucose concentrations (a) $4.91 \mathrm{mM}$; (b) $7.71 \mathrm{mM}$; (c) $9.73 \mathrm{mM}$ and (d) $15.42 \mathrm{mM}$. The solid black line and red dash line are before and after adding the human serum samples.

\section{CONCLUSION}

We successfully applied the electrochemically deposited method to the synthesis of the $\mathrm{Cu} / \mathrm{ITO}$ electrode, followed by an oxidation process at temperature of $400{ }^{\circ} \mathrm{C}$ in air to fabricate the $\mathrm{CuO} / \mathrm{ITO}$ electrode for glucose sensing. In terms of the electrode: $\mathrm{CuO}-\mathrm{C} / \mathrm{ITO}, \mathrm{CuO}-\mathrm{H} / \mathrm{ITO}$, and $\mathrm{CuO}-\mathrm{N} / \mathrm{ITO}$, we found out that the $\mathrm{CuO}-\mathrm{N} / \mathrm{ITO}$ electrode is the best for glucose sensing by investigating the cyclic voltammetry method. The CuO-N/ITO electrode for glucose determination using the chronoamperometric method showed a linear range of $1 \mu \mathrm{M}$ to $3600 \mu \mathrm{M}$ with a sensitivity of $283.6 \mu \mathrm{Acm}^{-2} \mathrm{mM}^{-1}$ and detection limit of $0.61 \mu \mathrm{M}$. The CuO-N/ITO electrode was also investigated with a human serum sample indicated a high potential towards a commercial section of the non enzymatic glucose sensor. 


\section{ACKNOWLEDGMENT}

This research is funded by Vietnam National Foundation for Science and Technology Development (NAFOSTED) under grant number 103.02-2016.63.

\section{REFERENCES}

[1] N.Q. Dung, D. Patil, T.T. Duong, H. Jung, D. Kim, S.G. Yoon, Sensors Actuators B Chem. 166-167 (2012) 103.

[2] N.Q. Dung, D. Patil, H. Jung, D. Kim, Biosens. Bioelectron. 42 (2013) 280.

[3] N.Q. Dung, D. Patil, H. Jung, J. Kim, D. Kim, Sensors Actuators B Chem. 183 (2013) 381.

[4] N.Q. Dung, T.T.T. Duong, T.D. Lam, D.D. Dung, N.N. Huy, D. Van Thanh, J. Electroanal. Chem. 848 (2019) 113323.

[5] L.C. Clark, C. Lyons, Ann. N. Y. Acad. Sci. 102 (1962) 29.

[6] M. Viticoli, A. Curulli, A. Cusma, S. Kaciulis, S. Nunziante, L. Pandolfi, F. Valentini, G. Padeletti, Mater. Sci. Eng. C 26 (2006) 947.

[7] K.M. El Khatib, R.M.A. Hameed, Biosens. Bioelectron. 26 (2011) 3542.

[8] Y. Wei, Y. Li, X. Liu, Y. Xian, G. Shi, L. Jin, Biosens. Bioelectron. 26 (2010) 275.

[9] B. Yuan, C. Wang, L. Li, S. Chen, Electrochem. Commun. 11 (2009) 1373.

[10] L.C. Jiang, W.D. Zhang, Biosens. Bioelectron. 25 (2010) 1402.

[11] X. Liu, L. Long, W. Yang, L. Chen, J. Jia, Sensors Actuators B. Chem. 266 (2018) 853.

[12] G. He, L. Wang, Can. J. Anesth. 24 (2018) 3167.

[13] R. Li, X. Liu, H. Wang, Y. Wu, K.C. Chan, Z. Lu, Electrochim. Acta 299 (2019) 470.

[14] M.S. Jagadeesan, K. Movlaee, T. Krishnakumar, S.G. Leonardi, G. Neri, J. Electroanal. Chem. 835 (2019) 161.

[15] X. Xiao, H. Li, Y. Pan, P. Si, Talanta. 125 (2014) 366.

[16] S. Yang, G. Li, D. Wang, Z. Qiao, L. Qu, Sensors Actuators B Chem. 238 (2017) 588.

[17] D. Jiang, Q. Liu, K. Wang, J. Qian, X. Dong, Z. Yang, X. Du, B. Qiu, Biosens. Bioelectron. 54 (2014) 273.

[18] M. Saraf, K. Natarajan, S.M. Mobin, Dalt. Trans. 45 (2016) 5833.

[19] T.K. Huang, K.W. Lin, S.P. Tung, T. M. Cheng, I.C. Chang, Y.Z. Hsieh, C.Y. Lee, H.T. Chiu, J. Electroanal. Chem. 636 (2009) 123.

[20] Q. Liu, Z. Jiang, Y. Tang, X. Yang, M. Wei, M. Zhang, Sensors Actuators B Chem. 255 (2018) 454.

[21] M. Figiela, M. Wysokowski, M. Galinski, T. Jesionowski, I. Stepniak, Sensors Actuators B Chem. 272 (2018) 296.

[22] C. Y. Chiang, K. Aroh, N. Franson, V. R. Satsangi, S. Dass, S. Ehrman, Int. J. Hydrogen Energy. 36 (2011) 15519.

[23] C.Y. Chiang, Y. Shin, K. Aroh, S. Ehrman, Int. J. Hydrogen Energy 37 (2012) 8232.

[24] S. M. Cha, G. Nagaraju, S. C. Sekhar, J. S. Yu, J. Mater. Chem. A. 5 (2017) 2224.

[25] C. R. Crick, I. P. Parkin, J. Mater. Chem. 21 (2011) 14712.

[26] Z.Y. Tian, H.J. Herrenbrück, P. M. Kouotou, H. Vieker, A. Beyer, A. Gölzhäuser, K. Kohse-Höinghaus, Surf. Coatings Technol. 230 (2013) 33.

[27] A. Kowalik-Klimczak, E. Stanisławek, J. Kacprzyñska-Gołacka, B. Kaźmierczak, P. Wieciñski, J. Mach. Constr. Maintenance Probl. Eksploat. 3 (2018) 49.

[28] D. Grujicic, B. Pesic, Electrochim. Acta 47 (2002) 2901. 